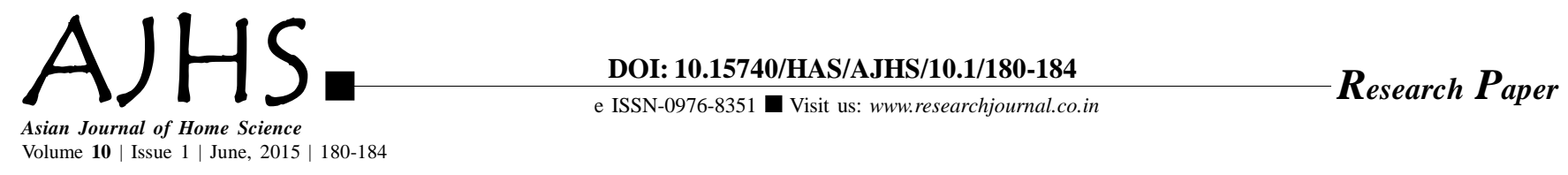

\title{
Assessment of obesity in school going children of different schools
}

\author{
PUNAM AGARWAL AND VISHAKHA SINGH
}

Received: 13.04.2015; Revised: 22.04.2015; Accepted: 18.05.2015

See end of the paper for authors' affiliations PUNAM AGARWAL

Department of Foods and Nutrition, College of Home Science, Orissa University of Agriculture and Technology, BHUBANESWAR (ODISHA) INDIA Email : punamagarwal2011@gmail.com
ABSTRACT : Unhealthy eating patterns and lack of physical activity develop obesity in school going children. If childhood obesity persists, it may bring the child at risk stage in his adolescent and adulthood. A study was undertaken on children from different schools in Bhubaneswar, Orissa to identify nutritional status based on anthropometric measurements and dietary intakes. Approximately 8.3 per cent boys (4-6 years age) in GEMS; 25 per cent boys in PNS and GEMS and 66.66 per cent girls of 7-9 years age in GEMS were stunted. About 50-75 per cent children in 7-9 years age group recorded normal to +1 (Z-score) BMI in PNS and GEMS whereas, 66.4 per cent boys and 91.63 per cent girls in SXHS (high parental income group) recorded BMI normal to +2 (Z-score). The data also indicated that around 8.33per cent girls and 25per cent boys of SXHS were obese with BMI of +3 . The income of the parents had profound influence on their calorie consumption and weight of school going children.

- KEY WORDS: BMI, Parental income, Anthropometric, Energy consumption

- HOW TO CITE THIS PAPER : Agarwal, Punam and Singh, Vishakha (2015). Assessment of obesity in school going children of different schools. Asian J. Home Sci., 10 (1) : 180-184. 